\title{
Epidemiology of Melanoma in the Czech Republic in East Bohemia in the Period 2002-2017 and the Effect of the Annual Sunshine Exposure
}

\author{
Jarmila Čelakovská1,*, Josef Bukač², Lenka Čáková1, Marie Šimková1, Eva Jandová1
}

\begin{abstract}
Aim: The evaluation of the trend in the occurrence of melanoma nodulare, melanoma superficiale, lentigo maligna and melanoma in situ in the period of 2002-2017 in East Bohemia region in the Czech Republic. We examine if the annual numbers of hours of sunshine could affect the number of patients with melanoma. Method: In the peridod of 2002-2017, altogether 2230 patients with new diagnosis of melanoma were examined. We studied 1) If there is some trend in the occurrence of lentigo maligna and melanoma in situ, melanoma superficiale, and melanoma nodulare and if there is a difference in the age of patients with this diagnosis (adjusted calculation of specific kind of melanomas and adjusted calculation of age). 2) If the annual numbers of hours of sunshine affect the trend in the occurrence of melanoma and if the annual numbers of hours of sunshine affect the body site of melanoma. Results and conclusion: Our study confirmed that the number of patients with lentigo maligna and melanoma in situ had increased in East Bohemia region in the period of 2002-2017. The number of melanomas of nodular and superficial type does not increase. The total number of melanomas in this period does not increase either. No difference of the age of patients with melanoma nodulare, superficiale, lentigo maligna and melanoma in situ was confirmed. We confirmed no relation of the annual numbers of hours of sunshine to the number of melanoma and to the body site of melanoma.
\end{abstract}

\section{KEYWORDS}

melanoma; sunshine exposure; lentigo maligna; melanoma in situ; adjusted calculation

\section{AUTHOR AFFILIATIONS}

${ }^{1}$ Department of Dermatology and Venereology Faculty Hospital and Medical Faculty of Charles University, Hradec Králové, Czech Republic

2 Department of Medical Biophysics, Medical Faculty of Charles University, Hradec Králové, Czech Republic

* Corresponding author: Department of Dermatology and Venereology, Faculty Hospital and Medical Faculty of Charles University, Hradec Králové, Czech Republic; e-mail: Celakovskaj@lfhk.cuni.cz 


\section{INTRODUCTION}

There is a universal agreement that the incidence of melanoma diagnoses increases and a similar trend has been observed in Europe, but the higher melanoma incidence has not been fully explained (1-5). Multiple studies using the US Surveillance, Epidemiology and End Results (SEER) Program and National Program of Cancer Registries have consistently reported increasing melanoma incidence between 1973 and 1997 (6-8). More recent studies (1992-2006) reported that melanoma incidence increased by $3 \%$ to $4 \%$ per year across most demographic groups $(1,9)$. Melanoma arises through multiple different causal pathways and reflects a dynamic interdependence between environmental factors and genetic alterations. Several factors have been identified that significantly influence the incidence and the clinical and oncogenic characteristics of this disease. These factors mainly comprise increased UV exposure, tanning bed use, family and personal history of melanoma, and certain phenotypical characteristics, such as fair skin and hair color. Epidemiological data support two major pathways in the pathogenesis of cutaneous melanoma: one by cumulative sun exposure to the site of the future melanoma in sun sensitive people and other by early sun exposure and nevus proneness, promoted by host factors, intermittent sun exposure, or both (11-18).

THE AIM OF THIS STUDY IS TO EVALUATE:

1) If there is some change in the occurrence of lentigo maligna, melanoma in situ, melanoma superficiale and melanoma nodulare from the year 2002 to the year 2017 (the incidence) and if there is some change in age of melanoma diagnosis.

2) If the annual numbers of hours of sunshine could affect the number of patients suffering from melanoma nodulare, superficiale, lentigo maligna and melanoma in situ.

3) If there is some relation between the annual numbers of hours of sunshine and the body site of melanoma (lentigo maligna, melanoma in situ, melanoma superficiale and melanoma nodulare).

\section{PATIENTS AND METHODS}

All patients included in this study were examined at the Department of Dermatology, Faculty Hospital, Hradec Králové, Charles University, Czech Republic. The diagnosis of melanoma was made according to its histology. Patients' information and degree of spread of the melanoma was obtained during the examination at out-patient department at the Department of Dermatology, Faculty Hospital, Hradec Králové, Charles University, Czech Republic.

\section{WE EVALUATED THE FOLLOWING DATA:}

1) If there are some changes in the occurrence of lentigo maligna, melanoma in situ, melanoma superficiale and melanoma nodulare from the year 2002 to the year
2017 (the incidence) and if there is some change in age of diagnosis.

2) If the annual number of hours of sunshine could affect the number of patients suffering from melanoma nodulare, superficiale, lentigo maligna and melanoma in situ.

3) If there is some relation between the annual numbers of hours of sunshine and the body site of melanoma (lentigo maligna, melanoma in situ, melanoma superficiale, and melanoma nodulare).

The data about the annual numbers of hours of sunshine were obtained from the Hydro-metereological Institute in Hradec Králové.

\section{STATISTICAL ANALYSIS}

We evaluated

1) If there is some trend in the occurrence of lentigo maligna, melanoma in situ, melanoma superficiale and melanoma nodulare from the year 2002 to the year 2017 and if there is some difference in age of diagnosis (the incidence). We studied the dependence of the adjusted number of patients on the year of the first occurrence/diagnosis.

2) If the annual numbers of hours of sunshine could affect the number of patients suffering from melanoma nodulare, superficiale, lentigo maligna and melanoma in situ.

3) If there is some relation between the annual numbers of hours of sunshine and the body site of melanoma (lentigo maligna, melanoma in situ, melanoma superficiale, and melanoma nodulare). The data about annual number of hours of sunshine were obtained from the Hydro - metereological Institute in Hradec Králové. To analyse the data we used the multiple regression model. We also included the number of hours from the previous two years as a lag variable because it could effect the formation of melanoma in the following year.

The age distribution changes year after year. This is the reason why we have to use standardization to be able to compare the number of patients in various years. We used the year 2017 as a standard. In each year we formed age groups five years wide, that is, $0-4,5-9,10-14$, etc. In each year we counted the number of patients with a certain type of melanoma for each group and divided it by the number of inhabitants in that group in the given year. That gave us the age-specific incidence. When we multiplied it by the number of inhabitants in the age group in the standard year, we obtained what we called an adjusted number of patients in the age group for the given year. We added the adjusted numbers over all the age groups in the given year to obtain an adjusted number of patients in that year.

To calculate the average age of patients in a given year, we followed the idea that is used when we calculate the mean when only a histogram is presented. We took the midpoint of each group in a given year, multiplied it by the adjusted number of patients in the group and summed the products up over all the groups in the given year. When the sum of products obtained in this manner was divided 
by the adjusted number of patients in that year, it gave us the adjusted average age in that year.

Unfortunately, major administrative changes were made as to the division of the country into smaller regions during the year 2001. These changes made the distributions of ages incomparable and intractable. This was the reason why we could make adjustment to numbers of patients and calculations of adjusted ages only beginning with the year 2002. Since the year 2017 was the last one in which the patients' data were recorded, sixteen years of adjusted numbers and ages of patients were available.

\section{RESULTS}

In the period 2002-2017, altogether 2230 patients with new diagnosis of melanoma were examined, 1102 men (49.4\%) and 1128 women (51.6\%). The cases of mucosal, desmoplastic melanoma and melanoma of unknown origin are also included in the whole number of melanomas examined in this period. The total number of patients (men, women) with new diagnosis of melanoma in every year of this period is shown in Table 1.

The statistical evaluation of the trend in the occurrence of new melanoma (total number of all kinds of melanomas) and the age of the diagnosis in the period of 2002-2017 was performed (adjusted number of patients with melanoma and adjusted average age of diagnosis) - Table 2. The difference in the occurrence of the total number of melanoma in the period 2002-2017 was not confirmed - Graph to Table 2. The change in age of melanoma diagnosis was not confirmed either. Regarding the histology, lentigo maligna and melanoma in situ was confirmed in 441 patients,

Tab. 1 Number of patients with new diagnosis of melanoma in the years $2002-2017$ (2230 patients $=100 \%)$.

\begin{tabular}{|l|r|r|r|l|c|}
\hline Year & \multicolumn{1}{l|}{ Men } & \multicolumn{1}{l|}{ \% } & Women & $\%$ & $\begin{array}{l}\text { Total } \\
\text { patients }\end{array}$ \\
\hline 2002 & 54 & 44.6 & 67 & 55.4 & 121 \\
\hline 2003 & 49 & 45.8 & 58 & 54.2 & 107 \\
\hline 2004 & 71 & 49.3 & 73 & 50.7 & 144 \\
\hline 2005 & 72 & 51.8 & 67 & 48.2 & 139 \\
\hline 2006 & 53 & 45.3 & 64 & 54.7 & 117 \\
\hline 2007 & 68 & 52.3 & 62 & 47.7 & 130 \\
\hline 2008 & 71 & 50.0 & 71 & 50.0 & 142 \\
\hline 2009 & 85 & 55.2 & 69 & 44.8 & 154 \\
\hline 2010 & 56 & 49.6 & 57 & 50.4 & 113 \\
\hline 2011 & 59 & 44.4 & 74 & 55.6 & 133 \\
\hline 2012 & 82 & 48.2 & 88 & 51.8 & 170 \\
\hline 2013 & 63 & 46.3 & 73 & 53.7 & 136 \\
\hline 2014 & 79 & 52.0 & 73 & 48.0 & 152 \\
\hline 2015 & 76 & 52.4 & 69 & 47.6 & 145 \\
\hline 2016 & 82 & 46.6 & 94 & 53.4 & 176 \\
\hline 2017 & 82 & 54.3 & 69 & 45.7 & 151 \\
\hline Total patients & 1102 & & 1128 & & 2230 \\
\hline p-value & 0.887 & & & & \\
\hline & & & & \\
\hline
\end{tabular}

melanoma nodulare in 388 patients and melanoma superficiale in 1404 patients, 55 of them suffered from multiple melanomas.

1) The evaluation, if there is some change in the occurrence of lentigo maligna, melanoma in situ, melanoma superficiale, and melanoma nodulare from the year 2002 to the year 2017 and if there is some change in age of diagnosis.

We studied the dependence of the adjusted number of patients on the year of the first occurrence/diagnosis. The statistical evaluation of the difference of the occurrence of melanoma nodulare, superficiale, lentigo malig-

Tab. 2 The trend in the occurrence of new melanoma and the age of diagnosis in the period of 2002-2017 was performed (adjusted number of patients with melanoma and adjusted average age of diagnosis). The change in the occurrence of melanoma in the period 2002-2017 was not confirmed. The change in age of melanoma diagnosis was not confirmed either.

\begin{tabular}{|l|c|c|}
\hline Year & $\begin{array}{l}\text { Adjusted number } \\
\text { of patients }\end{array}$ & $\begin{array}{l}\text { Adjusted age } \\
\text { of patients }\end{array}$ \\
\hline 2002 & 140.9 & 62.1 \\
\hline 2003 & 122.0 & 59.3 \\
\hline 2004 & 162.9 & 59.5 \\
\hline 2005 & 158.5 & 62.9 \\
\hline 2006 & 131.7 & 60.2 \\
\hline 2007 & 141.8 & 60.2 \\
\hline 2008 & 157.2 & 63.3 \\
\hline 2009 & 167.7 & 61.3 \\
\hline 2010 & 117.7 & 60.2 \\
\hline 2011 & 134.8 & 59.8 \\
\hline 2012 & 178.9 & 59.2 \\
\hline 2013 & 143.8 & 60.5 \\
\hline 2014 & 155.9 & 60.4 \\
\hline 2015 & 145.9 & 60.7 \\
\hline 2016 & 177.4 & 60.2 \\
\hline 2017 & 151.0 & 61.3 \\
\hline$p-v a l u e$ & 0.230 & 0.617 \\
\hline
\end{tabular}

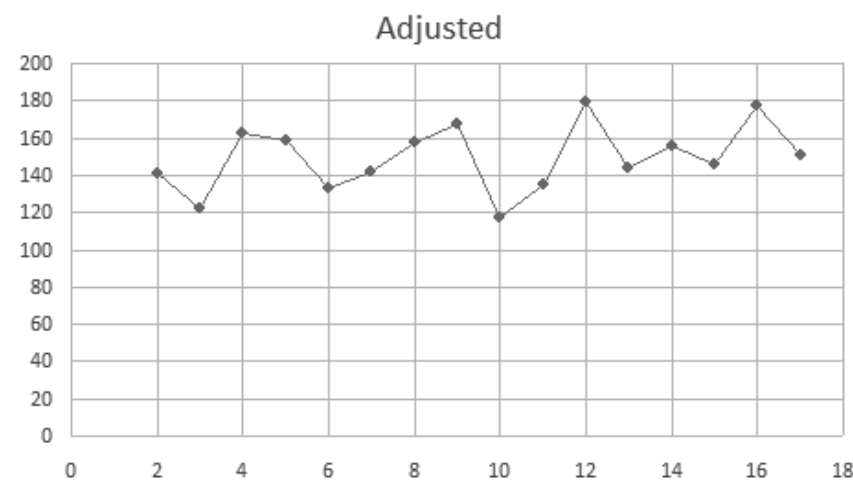

Graph to Table 2 The changes in the occurrence of new melanoma (total number of melanoma) in the period of 2002-2017 (adjusted number of patients with melanoma was calculated). The increase in the occurrence of melanoma in the period 2002-2017 was not confirmed, ( $x$ - axis: year, $y$ - axis: the adjusted number of patients with all kinds of melanomas). 
na and melanoma in situ in the period of 2002-2017 was performed (adjusted number of patients with melanoma nodulare, superficiale, lentigo maligna and melanoma in situ). The difference in the occurrence of melanoma nodulare and superficiale was not confirmed ( $p$-value $=0.248$, $p$-value $=0.753$ ), the difference in the occurrence of lentigo maligna and melanoma in situ in the period 2002-2017 was confirmed $(p$-value $=0.00037)$ - Table 3 , Graph to Table 3.

Tab. 3 The changes in the occurrence of melanoma nodulare, superficiale, lentigo maligna and melanoma in situ in the period of 2002-2017 was performed (adjusted number of patients with melanoma nodulare, superficiale, lentigo maligna and melanoma in situ). The difference in the occurrence of melanoma nodulare and superficiale was not confirmed ( $p$-value $=0.248$, $p$-value $=0.753$ ), the changes in the occurrence of lentigo maligna and melanoma in situ in the period 2002-2017 was confirmed ( $p$-value $\left.=0.0004^{*}\right)$.

\begin{tabular}{|l|c|c|c|}
\hline \multicolumn{4}{|l|}{ Adjusted number of patients } \\
\hline Year & $\begin{array}{l}\text { Lentigo maligna, } \\
\text { melanoma in situ }\end{array}$ & $\begin{array}{l}\text { Melanoma } \\
\text { nodulare }\end{array}$ & $\begin{array}{l}\text { Melanoma } \\
\text { superficiale }\end{array}$ \\
\hline 2002 & 13.7 & 26.7 & 100.5 \\
\hline 2003 & 18.1 & 25.7 & 78.3 \\
\hline 2004 & 20.4 & 35.4 & 107.1 \\
\hline 2005 & 14.1 & 36.0 & 108.3 \\
\hline 2006 & 25.5 & 30.3 & 75.9 \\
\hline 2007 & 23.0 & 31.4 & 87.4 \\
\hline 2008 & 24.6 & 20.3 & 112.4 \\
\hline 2009 & 38.0 & 18.9 & 110.7 \\
\hline 2010 & 20.2 & 17.0 & 80.5 \\
\hline 2011 & 30.3 & 30.2 & 74.4 \\
\hline 2012 & 37.5 & 28.9 & 112.5 \\
\hline 2013 & 31.4 & 32.0 & 80.4 \\
\hline 2014 & 36.0 & 26.2 & 93.7 \\
\hline 2015 & 32.4 & 23.6 & 90.0 \\
\hline 2016 & 57.3 & 22.4 & 97.7 \\
\hline 2017 & 32 & 26 & 93 \\
\hline$p$-value & $0.0004^{*}$ & 0.248 & 0.753 \\
\hline & & & \\
\hline
\end{tabular}

Adjusted Number of Patients

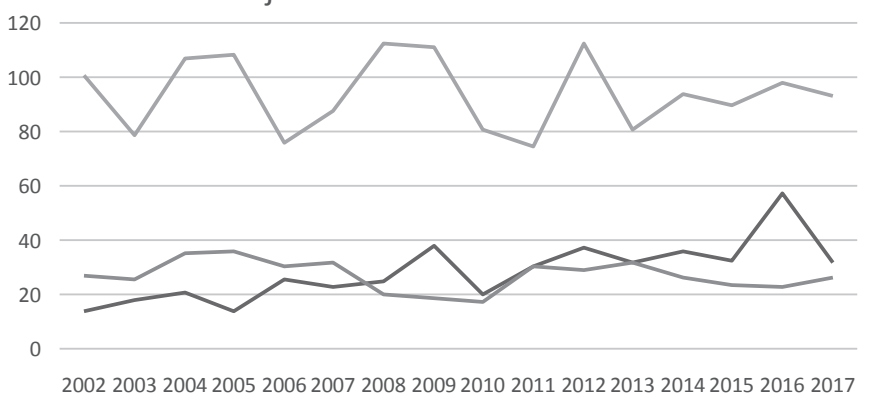

- NLMMis $\longrightarrow$ Nnod $\longrightarrow$ Nsup

Graph to Table 3 The trend in the occurrence of melanoma nodulare, superficiale, lentigo maligna and melanoma in situ in period 2002-2017 was performed (adjusted number of patients with melanoma nodulare, superficiale, lentigo maligna and melanoma in situ), (axis $x$ - year, axis $y$ - the adjusted number of patients with specific kind of melanoma, blue - lentigo maligna a and melanoma in situ, black - melanoma superficiale, red - melanoma nodulare).
The statistical evaluation of the change in the age of the diagnosis in patients with melanoma nodulare, superficiale, lentigo maligna and melanoma in situ (adjusted average age of diagnosis) was performed. The difference in the age of patients with melanoma nodulare, superficiale, lentigo maligna and melanoma in situ in the period of 2002-2017 was not confirmed - Table 4, Graph to Table 4.

2) The evaluation if the annual numbers of hours of sunshine could affect the number of patients suffering from melanoma nodulare, superficiale, lentigo maligna and melanoma in situ.

Tab. 4 The change in the age of the diagnosis in patients with melanoma nodulare, superficiale, lentigo maligna and melanoma in situ (adjusted average age of diagnosis). The difference of the age in patients with melanoma nodulare, superficiale, lentigo maligna and melanoma in situ in the period 2002-2017 was not confirmed.

\begin{tabular}{|l|c|c|c|}
\hline \multicolumn{4}{|c|}{ Adjusted average age of diagnosis } \\
\hline Year & $\begin{array}{l}\text { Lentigo maligna, } \\
\text { melanoma in situ }\end{array}$ & $\begin{array}{l}\text { Melanoma } \\
\text { nodulare }\end{array}$ & $\begin{array}{l}\text { Melanoma } \\
\text { superficiale }\end{array}$ \\
\hline 2002 & 63.4 & 67.8 & 60.3 \\
\hline 2003 & 59.4 & 54.6 & 60.8 \\
\hline 2004 & 51.5 & 64.8 & 59.2 \\
\hline 2005 & 63.1 & 69.4 & 60.9 \\
\hline 2006 & 55.2 & 67.7 & 58.9 \\
\hline 2007 & 58.6 & 63.0 & 59.6 \\
\hline 2008 & 56.2 & 67.8 & 64.0 \\
\hline 2009 & 62.3 & 66.8 & 59.9 \\
\hline 2010 & 53.4 & 65.4 & 60.8 \\
\hline 2011 & 58.7 & 64.8 & 58.2 \\
\hline 2012 & 57.2 & 67.9 & 57.7 \\
\hline 2013 & 54.3 & 67.5 & 60.2 \\
\hline 2014 & 59.7 & 63.2 & 59.8 \\
\hline 2015 & 58.8 & 63.3 & 60.8 \\
\hline 2016 & 60.0 & 65.7 & 59.0 \\
\hline 2017 & 65.3 & 63.0 & 59.5 \\
\hline$p-v a l u e$ & 0.632 & 0.933 & 0.405 \\
\hline
\end{tabular}

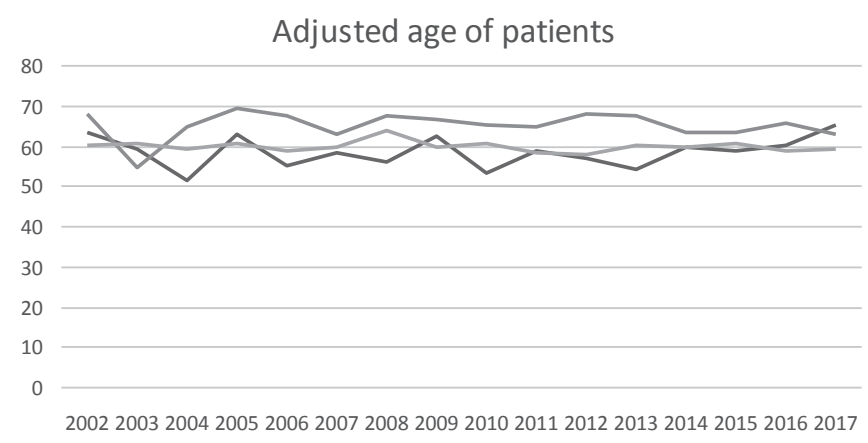

$$
\text { _ AgeLMMis Agenod Agesup }
$$

Graph to Table 4 The trend of the age of the diagnosis in patients with melanoma nodulare, superficiale, lentigo maligna and melanoma in situ with (adjusted average age of diagnosis ( $x$ - axis: year, $y$ - axis: the adjusted age, blue - lentigo maligna a and melanoma in situ, black - melanoma superficiale, red - melanoma nodulare). 
It turns out that the number of patients was independent of the number of hours of sunshine. All the $p$-values regarding the regression coefficients associated with the number of hours of sunshine were greater than 0.05 indicating the acceptance of the null hypothesis that these coefficients are zero which means independence. The length of sunshine in hours in every year in the period 2002-2017 and the total number of melanomas, number of melanoma nodulare, superficiale, lentigo maligna and melanoma in situ is shown in Table 5.

3) The evaluation if there is some relation between the annual numbers of hours of sunshine and the body site of melanoma (lentigo maligna, melanoma in situ, melanoma superficiale, and melanoma nodulare.

We also examined the effect of the number of hours of sunshine per year on numbers of melanoma with various locations on the body. Upper, lower limbs, and face were put together as they form a location exposed to sun. We used a regression model to determine whether there is any dependence of the number of melanomas on hours of sunshine. The relation between the number of melanomas (lentigo maligna, melanoma in situ, melanoma nodulare, melanoma superficiale) in body site exposed to sun (face, upper limbs, lower limbs) and the annual length of sunshine in hours is shown in Table 6. In all the cases the $p$-values were larger than 0.05 , which means no dependence was confirmed. The relation between number of melanomas on face (lentigo maligna, melanoma in situ, melanoma nodulare, melanoma superficiale) and the annual length of sunshine in hours was not confirmed either - Table 7. In all the cases the $p$-values were larger than 0.05 , which means no dependence.We also included the number of hours from the previous one year and two years as a lag variable because it could affect the formation of melanoma in the following years - the relation was not confirmed either.

\section{DISCUSSION}

According to the literature, the incidence of melanoma steadily increases in both sexes and further improvement in primary prevention and early detection strategies is crucial (19). Yet the epidemiologic, genomic, and anatomic profiles of the disease significantly differ across the world and mostly depend on a constellation of environmental and (epi) genetic factors. In this study, we evaluated the changes in epidemiology of melanoma in the period from the year 2002 to the year 2017 in Eastern Bohemia region in the Czech Republic in central Europe. There are 551 thausand inhabitants in the region and its area is 4759 square $\mathrm{km}$. The advantage of our study is that all patients included in this study were personaly examined and were followed up at the Department of Dermatology, Faculty Hospital Hradec Králové, Charles University, Czech Republic. We studied the dependence of the adjusted number of patients on the year of the first occurrence/ diagnosis. The statistically important changes in the occurrence of melanoma nodulare and superficiale were not confirmed, but the increase in the occurrence lentigo

Tab. 5 The annual length of the sunshine in hours in the period 2002-2017 and the number of melanomas. The relation between total number of melanomas, lentigo maligna, melanoma in situ, melanoma nodulare, melanoma superficiale and annual length of sunshine in hours was not confirmed. We also included the number of hours from the previous one year* and two years* as a lag variable because it could effect the formation of melanoma in the following years - the relation was not confirmed.

\begin{tabular}{|c|c|c|c|c|c|}
\hline \multirow[b]{2}{*}{ Year } & \multirow[b]{2}{*}{ Annual sunshine hours } & \multicolumn{4}{|c|}{ Adjusted number of patients } \\
\hline & & $\begin{array}{l}\text { Lentigo maligna, } \\
\text { melanoma in situ }\end{array}$ & Melanoma nodulare & Melanoma superficiale & $\begin{array}{l}\text { Total number } \\
\text { of melanoma }\end{array}$ \\
\hline 2002 & 1795 & 13.7 & 26.7 & 100.5 & 140.9 \\
\hline 2003 & 2283 & 18.1 & 25.7 & 78.3 & 122.0 \\
\hline 2004 & 1791 & 20.4 & 35.4 & 107.1 & 162.9 \\
\hline 2005 & 2005 & 14.1 & 36.0 & 108.3 & 158.5 \\
\hline 2006 & 1939 & 25.5 & 30.3 & 75.9 & 131.7 \\
\hline 2007 & 1876 & 23.0 & 31.4 & 87.4 & 141.8 \\
\hline 2008 & 1784 & 24.6 & 20.3 & 112.4 & 157.2 \\
\hline 2009 & 1715 & 38.0 & 18.9 & 110.7 & 167.7 \\
\hline 2010 & 1700 & 20.2 & 17.0 & 80.5 & 117.7 \\
\hline 2011 & 1981 & 30.3 & 30.2 & 74.4 & 134.8 \\
\hline 2012 & 1931 & 37.5 & 28.9 & 112.5 & 178.9 \\
\hline 2013 & 1902 & 31.4 & 32.0 & 80.4 & 143.8 \\
\hline 2014 & 1729 & 36.0 & 26.2 & 93.7 & 155.9 \\
\hline 2015 & 1903 & 32.4 & 23.6 & 90.0 & 145.9 \\
\hline 2016 & 1710 & 57.3 & 22.4 & 97.7 & 177.4 \\
\hline 2017 & 1690 & 32 & 26 & 93 & 151.0 \\
\hline$p$-value & & 0.673 & 0.343 & 0.529 & 0.073 \\
\hline p-value* & & 0.191 & 0.113 & 0.524 & 0.076 \\
\hline
\end{tabular}


maligna and melanoma in situ in the period 2002-2017 was confirmed. We would like to make a comment on the fact, that it is not true, that the number of melanomas of nodular and superficial type increases. The total number of melanomas according to the adjusted calculation does not increase either. Nor did we confirm the difference in age of melanoma diagnosis (melanoma superficiale, melanoma nodulare, lentigo maligna and malenoma in situ) the age of melanoma diagnosis is approximately 60 years. Also, we did not confirme the differnece of the occurrence of melanoma between men and women. These results are in contrast to other studies. Data on melanoma from the majority of countries show a rapid increase of the incidence of this type of cancer with a slowing of the rate of incidence in the period of 1990-2000. Males are approximately 1.5 times more likely to develop a melanoma than females while, according to other studies, the different prevalence in both sexes must be analyzed in relation to age: the incidence rate of melanoma is grater in women than in men until they reach the age of 40 years, however, by 75 years of age, the incidence is almost 3 -times as high in men versus women (20). On the other hand, a recent study of the Centers for Disease Control and Prevention database suggests that incidence in New England states may be decreasing (10). At this study, melanoma death and incidence rates per state during 2003 and 2013 were re-

Tab. 6 The relation between number of melanomas (lentigo maligna, melanoma in situ, melanoma nodulare, melanoma superficiale) in body site exposed to sun (face, upper limbs, lower limbs) and the annual the length of sunshine in hours was not confirmed. We also included the number of hours from the previous one year* and two years as a lag variable because it could effect the formation of melanoma in the following years - the relation was not confirmed.

\begin{tabular}{|l|c|c|c|c|}
\hline & \multicolumn{4}{|l|}{ Adjusted number of melanomas } \\
\hline Year & $\begin{array}{l}\text { Annual } \\
\text { sunshine } \\
\text { hours }\end{array}$ & $\begin{array}{l}\text { Lentigo maligna, } \\
\text { melanoma in situ } \\
\text { exposed }\end{array}$ & $\begin{array}{l}\text { Melanoma } \\
\text { nodulare } \\
\text { exposed }\end{array}$ & $\begin{array}{l}\text { Melanoma } \\
\text { superficiale } \\
\text { exposed }\end{array}$ \\
\hline 2002 & 1795 & 5.8 & 16.9 & 51.6 \\
\hline 2003 & 2283 & 10.9 & 10.4 & 48.4 \\
\hline 2004 & 1791 & 11.1 & 15.7 & 49.9 \\
\hline 2005 & 2005 & 5.9 & 21.5 & 58.7 \\
\hline 2006 & 1939 & 15.5 & 15.3 & 49.6 \\
\hline 2007 & 1876 & 11.5 & 15.9 & 38.8 \\
\hline 2008 & 1784 & 13.1 & 13.1 & 64.4 \\
\hline 2009 & 1715 & 18.9 & 10.3 & 51.9 \\
\hline 2010 & 1700 & 10.9 & 9.8 & 37.9 \\
\hline 2011 & 1981 & 15.5 & 16.8 & 30.1 \\
\hline 2012 & 1931 & 19.7 & 20.7 & 64.3 \\
\hline 2013 & 1902 & 19.3 & 14.1 & 41.6 \\
\hline 2014 & 1729 & 17.7 & 9.5 & 51.1 \\
\hline 2015 & 1903 & 14.4 & 15.3 & 42.8 \\
\hline 2016 & 1710 & 33.1 & 6.1 & 52.9 \\
\hline 2017 & 1690 & 18 & 12 & 61 \\
\hline$p-v a l u e$ & & 0.145 & 0.185 & 0.852 \\
\hline$p-v a l u e^{*}$ & & 0.114 & 0.413 & 0.969 \\
\hline
\end{tabular}

corded. Rates were per 100000 persons and were age-adjusted to the 2000 standard population of the US Census Bureau's population projections series (10). Additional factors may have contributed to the observed increased melanoma incidence. Melanoma in situ (stage 0) lesions represent an increasingly larger percentage of the overall increase in melanoma incidence. For example, while there have been on average $2.6 \%$ annual increases in all US melanoma diagnoses in recent years, melanoma in situ diagnoses increased at an annual rate of 9.5\%. Similar trends have been noted in Europe and Australia (21, 22). These results are in agreement with the results of our study. The increased proportion of early-stage lesions suggests that factors related to overdiagnosis, screening, an increased number of biopsy specimens, and incomplete reporting may have contributed to the increased incidence of melanoma. One explanation for increased melanoma incidence with stable mortality is the misclassification by pathologists of biologically benign melanocytic lesions as melanoma. Although the histologic criteria for melanoma have been well-defined, it is not possible to predict the biologic behavior of lesions that share features overlapping with nevi and melanoma (23-26). On the other hand, it has been suggested that the melanoma "epidemic" is primarily the result of previous underdiagnosis rather than current overdiagnosis, resulting from improved

Tab. 7 The relation between number of melanomas on the face (lentigo maligna, melanoma in situ, melanoma nodulare, melanoma superficiale) and the annual length of sunshine in hours was not confirmed. We also included the number of hours from the previous one year* and two years as a lag variable because it could effect the formation of melanoma in the following years - the relation was not confirmed.

\begin{tabular}{|l|c|c|c|c|}
\hline & & \multicolumn{3}{|l|}{ Adjusted number of melanomas on the face } \\
\hline Year & $\begin{array}{l}\text { Annual } \\
\text { sunshine } \\
\text { hours }\end{array}$ & $\begin{array}{l}\text { Lentigo maligna, } \\
\text { melanoma in } \\
\text { situ }\end{array}$ & $\begin{array}{l}\text { Melanoma } \\
\text { nodulare }\end{array}$ & $\begin{array}{l}\text { Melanoma } \\
\text { superficiale }\end{array}$ \\
\hline 2002 & 1795 & 3.6 & 4.1 & 8.2 \\
\hline 2003 & 2283 & 6.3 & 3.4 & 10.3 \\
\hline 2004 & 1791 & 3.5 & 1.1 & 12.8 \\
\hline 2005 & 2005 & 2.8 & 4.7 & 17.5 \\
\hline 2006 & 1939 & 5.5 & 3.5 & 6.5 \\
\hline 2007 & 1876 & 4.6 & 4.9 & 7.1 \\
\hline 2008 & 1784 & 2.5 & 7.1 & 16.8 \\
\hline 2009 & 1715 & 5.8 & 2.5 & 15.1 \\
\hline 2010 & 1700 & 1.5 & 1.8 & 10.6 \\
\hline 2011 & 1981 & 4.1 & 2.6 & 6.7 \\
\hline 2012 & 1931 & 5.3 & 2.7 & 14.3 \\
\hline 2013 & 1902 & 3.1 & 2.1 & 8.8 \\
\hline 2014 & 1729 & 4.9 & 2.1 & 11.1 \\
\hline 2015 & 1903 & 2.1 & 5.2 & 5.3 \\
\hline 2016 & 1710 & 9.1 & 1.1 & 13.1 \\
\hline 2017 & 1690 & 7 & 2 & 18 \\
\hline$p$-value & & 0.818 & 0.191 & 0.468 \\
\hline$p$-value & & 0.321 & 0.232 & 0.706 \\
\hline & & & & \\
\hline
\end{tabular}


histologic diagnostic criteria that allow melanomas to be recognized more accurately and at earlier stages (27). There is also an important role of screening and increased biopsies. Skin cancer screenings sponsored by the American Academy of Dermatology began in 1985 and since that time increased melanoma awareness has resulted in an increasing fraction of the population being screened for melanoma $(28,29)$. Several studies have documented a correlation of increasing melanoma incidence with biopsy (30). Although the majority of increased melanoma diagnoses are represented by thin lesions, diagnosis of thicker lesions has also increased over the past decades (31). Melanoma incidence has increased without regard to socioeconomic status, which is a surrogate marker for access to care and screening, (32).

We evaluated also the relation between the length of sunshine in hours in every year in the period 2002-2017 and the total number of melanomas. It turns out that the number of patients was independent of the number of hours of sunshine. We also examined the effect of the number of hours of sunshine per year on numbers of melanoma with various locations on the body. The relation between the number of melanomas (lentigo maligna, melanoma in situ, melanoma nodulare, melanoma superficiale) in body site exposed to sun (face, upper limbs and lower limbs) and annual length of sunshine in hours was not confirmed. We also included the number of hours from the previous one year and two years as a lag variable because it could effect the formation of melanoma in the following years - the effect was not confirmed. According to the literature, there is a strong evidence that an intermittent pattern of sun exposure increases melanoma risk. Chronic sun exposure shows no association, or a weak inverse association with melanoma risk. Total lifetime sun exposure is positively associated with melanoma risk, but the relationship is weaker than that for intermittent sun exposure. Sunburn is a marker of an intermittent pattern of sun exposure and there is a tendency for greater consistency of positive associations for sunburn than for intermittent exposure; significantly higher risk was found for intermittent than chronic exposure among studies that published results for both exposures (33-42). The role of ultraviolet radiation exposure as a leading environmental cause of melanoma is supported by a wealth of descriptive evidence in the past, including a high prevalence of melanoma in populations that migrated from a low to a high ambient ultraviolet radiation environment, a higher incidence in fair skinned compared with darker skinned individuals and a latitude dependent rise in melanoma rates among white populations with proximity to the equator $(43,44)$. However, differences in rates between indoor and outdoor workers and variations in the anatomical distribution of the tumour suggest a complex association of melanoma with ultraviolet radiation that does not confirm a straightforward dose relationship model. A history of intermittent exposure to excess ultraviolet radiation doses and of painful sunburns, as a marker of host sensitivity, were a consistent finding in the majority of case-control studies and were confirmed in recent systematic reviews $(42,45)$.
According to the study by Swerdlow, the incidence of malignant melanoma of the skin has risen rapidly in England and Wales, especially in women. Mean incidences in the 14 English health regions and Wales correlated negatively with latitude and positively with hours of sunshine, suggesting that exposure to sunshine was an important causal factor. Male and female incidences within a region tended to show similar yearly fluctuations, implying a common factor affecting the incidence in both men and women with a short latent period of action. This factor may be exposure to sunshine, which may cause melanoma after an induction period of about two years; for women the incidence of melanoma in the regions of England and Wales correlated positively with hours of sunshine two years earlier (46).

Apart from environmental risk factors, phenotypic and genetic characteristics also have been consistently associated with an increased risk of melanoma development. Additionally, melanoma seems to appear more commonly in immunosuppressed patients, including patients with prior organ transplantation, hematologic malignancies, or human immunodeficiency virus infection, as well as patients taking immunosuppressive medication (47-59).

\section{CONCLUSION}

The number of patients with lentigo maligna and melanoma in situ increased. The number of melanomas of nodular and superficial type does not increase and the total number of melanomas does not increase either. No difference of the age in patients with melanoma nodulare, superficiale, lentigo maligna and melanoma in situ was confirmed. No relation of the annual numbers of hours of sunshine to the number of patients with new diagnosis of melanoma and to the body site of melanoma was confirmed either.

\section{REFERENCES}

1. Linos E, Swetter SM, Cockburn MG, Colditz GA, Clarke CA. Increasing burden of melanoma in the United States. J Investig Dermatol 2009; 129(7): 1666-74.

2. Surveillance, Epidemiology, and End Results (SEER). Program Cancer Statistics Review, 1975-2013, National Cancer Institute [Internet] Nov, 2015. SEER data submission [cited posted to the SEER web site, 2016 Apr]. Available from: http://seer.cancer.gov/csr/1975_2013/.

3. Erdei E, Torres SM. A new understanding in the epidemiology of melanoma. Exp Rev Anticancer Ther 2010; 10(11): 1811-23.

4. Giblin AV, Thomas JM. Incidence, mortality and survival in cutaneous melanoma. J Plast Reconstr Aesthet Surg 2007; 60: 32-40.

5. Garbe, C, Leiter U. Melanoma epidemiology and trends Clin Dermatol 2009; 27: 3-9.

6. Welch HG, Woloshin, S, Schwartz LM. Skin biopsy rates and incidence of melanoma: population based ecological study. BMJ 2005; 331: 481 .

7. Dennis LK. Analysis of the melanoma epidemic, both apparent and real: data from the 1973 through 1994 surveillance, epidemiology, and end results program registry. Arch Dermatol 1999; 135: 275-80.

8. Hall HI, Jamison P, Fulton JP, Clutter G, Roffers S, Parrish P. Reporting cutaneous melanoma to cancer registries in the United States. J Am Acad Dermatol 2003; 49: 624-30.

9. Jemal A, Saraiya M, Patel P, et al. Recent trends in cutaneous melanoma incidence and death rates in the United States, 1992-2006. J Am Acad Dermatol 2011; 65 (5 suppl 1): S17-S25, e1-3. 
10. Mounessa JS, Caravaglio, JV, Dellavalle RP. Comparison of regional and state differences in melanoma rates in the United States: 2003 vs 2013. AMA Dermatol 2017; 153: 345-7.

11. Koh HK, Geller AC, Miller, DR, Grossbart TA, Lew RA. Prevention and early detection strategies for melanoma and skin cancer. Current status Arch Dermatol 1996; 132(4): 436-43.

12. van der Leest, R, Flohil S, Arends L, de Vries E, Nijsten, T. Risk of subsequent cutaneous malignancy in patients with prior melanoma: a systematic review and meta-analysis. J Eur Acad Dermatol Venereol 2015; 29(6): 1053-62.

13. D'Orazio J, Jarrett S, Amaro-Ortiz A, Scott T. UV radiation and the skin. Int J Mol Sci 2013; 14(6): 12222-48.

14. Colantonio S, Bracken MB, Beecker J. The association of indoor tanning and melanoma in adults: systematic review and meta-analysis. J Am Acad Dermatol 2014; 70(5): 847-57.

15. Pawlak MT, Bui M, Amir M, Burkhardt DL, Chen AK, Dellavalle RP. Legislation restricting access to indoor tanning throughout the world. Arch Dermatol 2012; 148(9): 1006-12.

16. Bevona C, Goggins W, Quinn T, Fullerton J, Tsao H. Cutaneous melanomas associated with nevi. Arch Dermatol 2003; 139(12): 1620-4.

17. Haenssle HA, Mograby N, Ngassa A, et al. Association of patient risk factors and frequency of nevus-associated cutaneous melanomas. JAMA Dermatol 2016; 152(3): 291-8.

18. Whiteman DC, Stickley M, Watt P, Hughes MC, Davis MB, Green AC. Anatomic site, sun exposure, and risk of cutaneous melanoma. J Clin Oncol 2006; 24(19): 3172-7.

19. Siegel RL, Miller KD, Jemal A. Cancer statistics, 2017. CA Cancer J Clin 2017; 67(1): 7-30.

20. Rastrelli M, Tropea S, Rossi C, Alaibac, M. Melanoma, Epidemiology, Risk Factors, Pathogenesis, Diagnosis and Classification. In vivo 2014; 28(6): 1005-11.

21. Buettner PG, Leiter U, Eigentler TK, Garbe, C. Development of prognostic factors and survival in cutaneous melanoma over 25 years: an analysis of the Central Malignant Melanoma Registry of the German Dermatological Society. Cancer 2005; 103: 616-24.

22. Coory M, Baade P, Aitken C, Smithers M, McLeod GR, Ring I. Trends for in situ and invasive melanoma in Queensland, Australia, 1982-2002. Cancer Causes Control 2006; 17: 21-7.

23. Troxel DB. Pitfalls in the diagnosis of malignant melanoma: findings of a risk management panel study. Am J Surg Pathol 2003; 27: 1278-83.

24. Frangos JE, Duncan LM, Piris A, et al. Increased diagnosis of thin superficial spreading melanomas: a 20-year study. J Am Acad Dermatol 2012; 67: 387-94.

25. Glusac JE. The melanoma 'epidemic', a dermatopathologist's perspective. J Cutan Pathol 2011; 38: 264-7.

26. Shuster S. Malignant melanoma: how error amplification by screening creates spurious disease. Br J Dermatol 2009; 161: 977-9.

27. Weyers W. The 'epidemic' of melanoma between under- and overdiagnosis. J Cutan Pathol 2012; 39: 9-16.

28. Lakhani NA, Saraiya M, Thompson TD, King SC, Guy GP Jr. Total body skin examination for skin cancer screening among U.S. adults from 2000 to 2010. Prev Med 2014; 61: 75-80.

29. Geller AC, Zhang Z, Sober AJ, et al. The first 15 years of the American Academy of Dermatology skin cancer screening programs: 1985-1999. J Am Acad Dermatol 2003; 48: 34-41.

30. Hiatt RA, Fireman B. The possible effect of increased surveillance on the incidence of malignant melanoma. Prev Med 1986; 15: 652-60.

31. Criscione VD, Weinstock MA. Melanoma thickness trends in the United States, 1988-2006. J Invest Dermatol 2010, 130: 793-7.

32. Chen ST, Geller AC, Tsao H. Update on the epidemiology of melanoma. Curr Dermatol Rep 2013; 2: 24-34.

33. Beddingfield EC.3rdThe melanoma epidemic: res ipsa loquitur. Oncologist 2003; 8: 459-65.

34. Erickson C, Driscoll MC. Melanoma epidemic: facts and controversies. Clin Dermatol 2010; 28: 281-6.

35. Gilchrest BA, Eller MS, Geller AC, Yaar M. The pathogenesis of melanoma induced by ultraviolet radiation. N Engl J Med 1999; 340: 1341-8.

36. Dennis LK, Vanbeek MJ, Beane Freeman LE, Smith BJ, Dawson DV Coughlin JA. Sunburns and risk of cutaneous melanoma: does age matter? A comprehensive meta-analysis. Ann Epidemiol 2008; 18: 614-27.

37. Armstrong BK, Cust AC. Sun exposure and skin cancer, and the puzzle of cutaneous melanoma: a perspective on Fears et al. Mathemat- ical models of age and ultraviolet effects on the incidence of skin cancer among whites in the United States. American Journal of Epidemiology 1977; 105: 420-427. Cancer Epidemiol 2017; 48: 147-56.

38. Lazovich, D, Vogel RI, Berwick M, Weinstock MA, Warshaw EM, Anderson KE. Melanoma risk in relation to use of sunscreen or other sun protection methods. Cancer Epidemiol Biomarkers Prev 2011; 20: 2583-93.

39. Green AC, Williams GM, Logan V, Strutton, G.M.Reduced melanoma after regular sunscreen use: randomized trial follow-up. J Clin Oncol 2011; 29: 257-63.

40. Robinson JK, Rigel DS, Amonette RA. Trends in sun exposure knowledge, attitudes, and behaviors: 1986 to 1996. J Am Acad Dermatol 1997; 37: 179-86

41. Gandini, S, Sera F, Cattaruzza,MS, et al. Meta-analysis of risk factors for cutaneous melanoma: I. Common and atypical naevi. Eur J Cancer 2005; 41: 28-44.

42. Gandini S, Sera F, Cattaruzza MS, et al. Meta-analysis of risk factors for cutaneous melanoma: II. Sun exposure. Eur J Cancer 2005; 41 : 45-60.

43. Autier P, Doré JF, Gefeller O, et al. Melanoma risk and residence in sunny areas. EORTC Melanoma Co-operative Group. European Organization for Research and Treatment of Cancer. Br J Cancer 1997; 76: 1521-4.

44. Moan J, Dahlback A. The relationship between skin cancers, solar radiation and ozone depletion. Br J Cancer 1992; 65: 916-21.

45. lwood JM, Jopson J. Melanoma and sun exposure: an overview of published studies. Int J Cancer 1997; 73: 198-203.

46. Swerdlow AJ. Incidence of malignant melanoma of the skin in England and Wales and its relationship to sunshine. Br Med J 1979; 2(6201): 1324-7.

47. Caini S, Gandini S, Sera F, et al. Meta-analysis of risk factors for cutaneous melanoma according to anatomical site and clino-pathological variant. Eur J Cancer 2009; 45: 3054-63.

48. Olsen CM, Zens MS, Green AC, et al. Biologic markers of sun exposure and melanoma risk in women: pooled case-control analysis. Int J Cancer 2011; 129: 713-23.

49. Whiteman DC, Pavan WJ, Bastian BC. The melanomas: a synthesis of epidemiological, clinical, histopathological, genetic, and biological aspects, supporting distinct subtypes, causal pathways, and cells of origin. Pigment Cell Melanoma Res 2011; 24(5): 879-97.

50. Liu F, Bessonova L, Taylor TH, Ziogas A, Meyskens FL Jr, Anton-Culver $\mathrm{H}$. A unique gender difference in early onset melanoma implies that in addition to ultraviolet light exposure other causative factors are important. Pigment Cell Melanoma Res 2013; 26(1): 128-35.

51. Liu-Smith F, Farhat AM, Arce A, et al. Sex differences in the association of cutaneous melanoma incidence rates and geographic ultraviolet light exposure. J Am Acad Dermatol 2017; 76(3): 499-505, e3.

52. Liu-Smith F, Ziogas A. An age-dependent interaction between sex and geographical UV index in melanoma risk. J Am Acad Dermatol 2017; pii: S0190-9622(17)327482.

53. Howlader N, Noone AM, Krapcho M (eds). SEER cancer statistics review, 1975-2014, National Cancer Institute. Bethesda, MD, http:// seer.cancer.gov/csr/1975_2014/, based on November 2016 SEER data submission, posted to the SEER web site, April 2017.

54. Joosse A, Collette S, Suciu S, Nijsten T, Patel PM, Keilholz U, et al. Sex is an independent prognostic indicator for survival and relapse /progression-free survival in metastasized stage III to IV melanoma: a pooled analysis of five European organisation for research and treatment of cancer randomized controlled trials. J Clin Oncol 2013; 31(18): 2337-46.

55. Courtenay WH. Constructions of masculinity and their influence on men's well-being: a theory of gender and health. Soc Sci Med 2000; 50(10): 1385-401

56. Watts CG, Madronio C, Morton RL, et al. Clinical features associated with individuals at higher risk of melanoma: a population-based study. JAMA Dermatol 2017; 153(1): 23-9.

57. Barysch MJ, Levesque MP, Cheng P, et al. Coexpression of SOX10/ CD271 (p75(NTR)) and beta-galactosidase in large to giant congenital melanocytic nevi of pediatric patients. Dermatopathology (Basel) $2014 ; 1(1): 35-46$.

58. Krengel S, Hauschild A, Schafer T. Melanoma risk in congenital melanocytic naevi: a systematic review. Br J Dermatol 2006; 155(1): 1-8.

59. Kubica A, Brewer J. Melanoma in immunosuppressed patients. Mayo Clin Proc 2012; 87(10): 991-1003. 